How can the comparability of early childhood education and care statistics be improved?

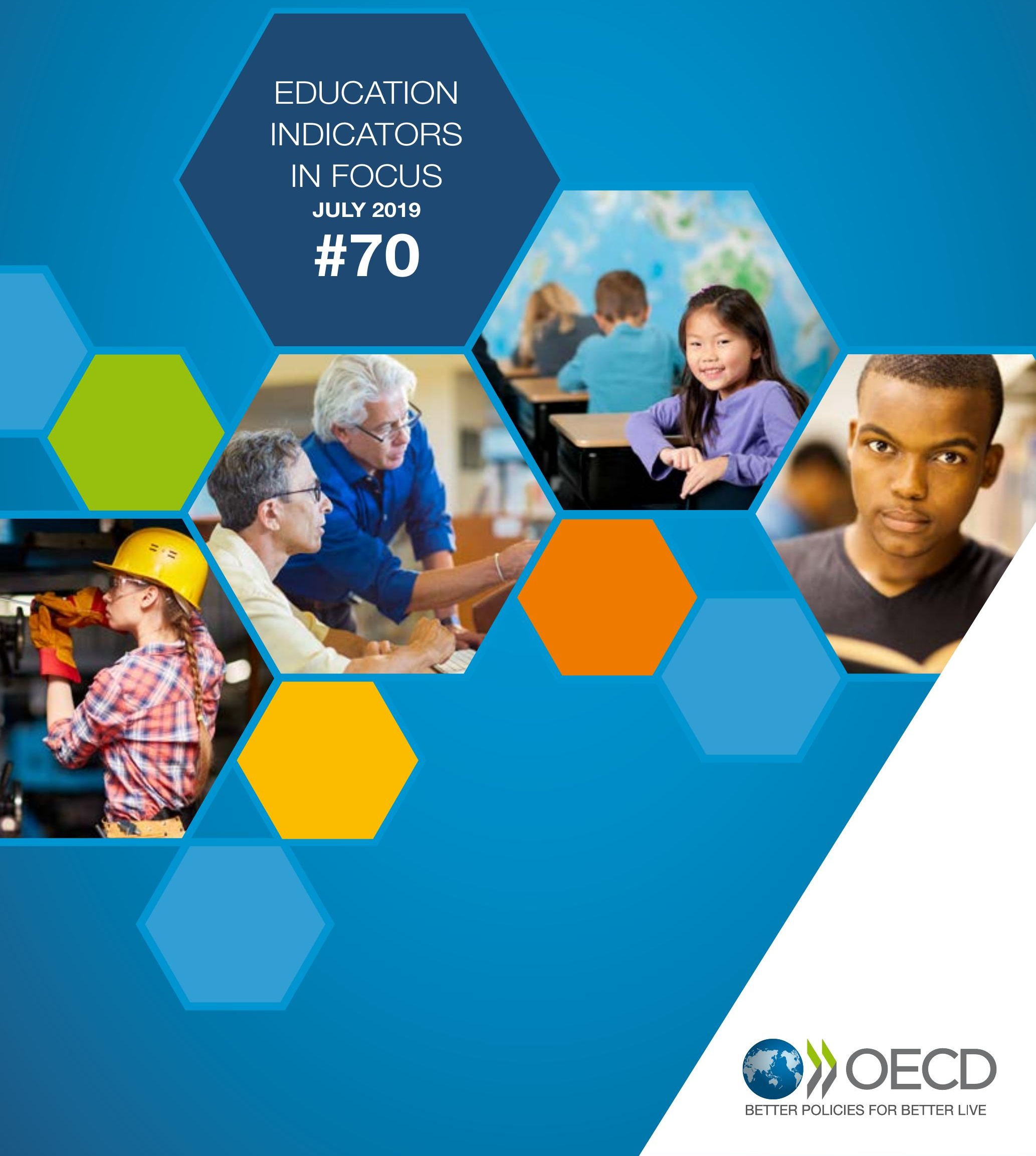


- The types of early childhood education and care (ECEC) services available to children and parents vary significantly both within and across OECD countries making international comparisons more complex than for any other level of education.

- The revised ISCED 2011 classification makes significant progress towards improving international comparison of ECEC services. The new version includes several criteria to better identify services with a similar level of educational content and captures for the first time services designed for children under the age of 3.

- But ISCED 2011 has some limitations. The classification excludes some well-developed ECEC services that are considered an integral part of ECEC provision in some countries but do not comply with all the ISCED 0 criteria. Their recent inclusion in enrolment statistics has enabled interesting new forms of analysis.

- While much progress has been made in recent years, more work is needed to develop ECEC indicators and to consider other characteristics that affect their interpretation and comparability across countries.

\section{Classifying early childhood education and care services}

There is a growing consensus among OECD countries about the importance of ECEC. Participation in high-quality ECEC can have a positive effect on children's well-being, learning and development in the first years of their lives. Despite this general trend, the types of ECEC services available to children and parents differ greatly across OECD countries, especially for very young children. They vary in the age groups targeted, the ownership of centres, the funding of services, the intensity of participation (i.e. usual number of hours per week), the type of delivery (full-day versus part-day attendance), staff qualifications, the care or education orientation of provision, and where services are provided (either in centres/schools or at home). In sum, formal ECEC services typically fall into one of the following categories (OECD, 2018[2]; OECD, 2017 ${ }_{[1]}$ ):

- Regular centre-based ECEC: More formalised ECEC centres typically belong to one of three sub-categories:

- Centre-based ECEC for children under the age of 3: Often called creches, these settings may have an educational function, but they are typically provided by the social or welfare sector and associated with an emphasis on care. Many of them are part time and provided in schools, but they can also be provided in designated ECEC centres.

- Centre-based ECEC for children from the age of 3: Often called kindergartens or preschool, these settings tend to be more formalised and are often under the authority of the education ministry.

- Age-integrated centre-based ECEC for children from birth or age 1 up to the beginning of primary school: Called kindergartens, preschool or pre-primary, these settings offer holistic pedagogical provision of education and care (often full-day) and are typically under the authority of the education ministry. Currently, over half of OECD countries offer this kind of services.

- $\quad$ Family childcare ECEC: Licensed home-based ECEC, which is most prevalent for children under 3 years old. These settings may or may not have an educational function and be part of the regular ECEC system.

- Licensed or formalised drop-in ECEC centres: Often receiving children across the entire ECEC age bracket and even beyond, these drop-in centres allow parents to complement home-based care by family members or family childcare with more institutionalised services on an ad-hoc basis (without having to apply for a place).

In addition to formal ECEC, informal care services (generally unregulated care arranged by the child's parent either in the child's home or elsewhere, provided by relatives, friends, neighbours, babysitters or nannies) also exist in many countries. However, these services are generally outside the scope of internationally comparable ECEC statistics.

\section{Classifying early childhood education and care services}

There are a range of different approaches to identifying the boundary between early childhood education and childcare. Some of the ECEC services listed above have intentional and well-developed educational objectives and are within the scope of ISCED-2011. Others are outside this scope, often because they are less structured and more care oriented, or have only a small educational component. The boundary between these categories is often blurred, hindering international comparisons of ECEC services. Among other goals, the revision of the ISCED classification in 2011 aimed to improve the definition of early childhood education and care and to better capture ECEC services designed for very young children (i.e. under the age of 3).

In this classification, ISCED level 0 is the first level and refers to early childhood programmes that have an intentional education component. Along with an intentional child-development and educational focus, a key defining factor of ISCED level 0 programmes is the sustained intensity and the duration of delivery of intentional educational activities. These are what differentiate ISCED level 0 services from other ECEC services outside the scope of ISCED. 
As the educational properties of ISCED 0 programmes can be difficult to assess directly, several additional criteria were added during the revision to develop a better technical definition. To qualify as an educational programme under the revised classification, ECEC services must (OECD/Eurostat/UNESCO Institute for Statistics, 2015 ${ }_{[3]}$ ):

- $\quad$ have adequate intentional educational properties

- be targeted at children within the age range starting from 0 or 1 up to the age when ISCED level 1 (primary) education starts

- be institutionalised (usually school-based or otherwise institutionalised for a group of children)

- have an intensity of at least 2 hours of educational activities per day and a duration of at least 100 days a year

- $\quad$ have a regulatory framework recognised by the relevant national authorities (e.g. a curriculum)

- $\quad$ have trained or accredited staff (e.g. educators are required to have pedagogical qualifications).

ISCED 0 programmes are sub-classified in ISCED 2011 into two categories depending on children's age and the level of complexity of the educational content (see Box 1): early childhood educational development (ISCED 01) and pre-primary education (ISCED 02). Early childhood educational development is a new category introduced with the revision of the ISCED classification. It has educational content designed for younger children (0-2 year-olds). Pre-primary is typically designed for children from the age of 3 to the start of primary education. It corresponds to level 0 in the earlier version of the classification, ISCED-97.

\section{Box 1. Educational properties of ISCED 0 programmes}

ISCED level 0 is typically designed to take a holistic approach towards supporting children's early cognitive, language, physical, social and emotional development and to introduce young children to organised instruction in an institutionalised setting.

ISCED 01: The learning environment is visually stimulating and language rich and fosters self-expression with an emphasis on language acquisition and the use of language for meaningful communication. There are opportunities for active play so that children can exercise their co-ordination and motor skills under supervision and in interaction with staff.

ISCED 02: Through interaction with peers and educators, children improve their use of language and their social skills, start to develop logical and reasoning skills, and talk through their thought processes. Supervised gross motor activities (i.e., physical exercise through games and other activities) and play-based activities can be used as learning opportunities to promote social interactions with peers and to develop skills, autonomy and school readiness.

Source: OECD/Eurostat/UNESCO Institute for Statistics (2015 $\left.{ }_{[3}\right)$, ISCED 2011 Operational Manual: Guidelines for Classifying National Education Programmes and Related Qualifications, http://dx.doi.org/10.1787/9789264228368-en

For data-reporting purposes, the distinction between ISCED 01 and ISCED 02 is based on the educational properties of the year, stage or cycle of the programme that a child is attending. If children below the age of 3 are enrolled in ISCED 02, then they should be reported as participating in ISCED 02. Age-integrated centre-based ECEC for children from birth or the age of 1 up to the beginning of primary school requires special attention. For these services, classification into ISCED 01 and ISCED 02 is based on the ages of children: data for children below the age of 3 should be reported as ISCED 01 and data for children aged 3 to the starting age for ISCED 1 should be reported as ISCED 02. This may involve the estimation of expenditure and personnel at levels 01 and 02.

\section{How ECEC services outside the scope of ISCED 0 are covered in education statistics?}

The revised ISCED 2011 classification offers significant progress and was implemented in international data collection in 2015. However, some ECEC services that are considered an integral part of countries' ECEC provision are not included in the ISCED classification because they do not comply with all the ISCED 0 criteria to be considered an educational programme. In some countries, a significant proportion of children are enrolled in such services. Including them offers a better overview of ECEC provision, which is why they are taken into account in enrolment statistics (see Box 2). The large majority of these additional ECEC services are designed for children under the age of 3. They are presented in indicators separately from ISCED 0 programmes because they are less education oriented (Figure 1).

This distinction offers interesting new dimensions for analysis. Thus, when women's employability and ECEC provision are analysed together, evidence shows that countries with higher enrolment rates of children under 3, regardless of the type of ECEC services available, tend to be those with the highest employment rates among mothers (OECD, 2018 $\left.8_{[2]}\right)$.

The analysis offered by this extended classification does also account for the quality of education provided to children by comparing types of ECEC provision. In Norway, for instance, not only do more than half of children below the age of 3 attend ECEC services, but they also attend programmes that meet all the ISCED criteria. Thus, children in Norway are more likely 
Figure 1 / Enrolment rates of children under the age of 3 in early childhood education and care, by type of service (2010 and 2016)

All ECEC services (early childhood education (ISCED 0) and other registered ECEC services outside the scope of ISCED 0)

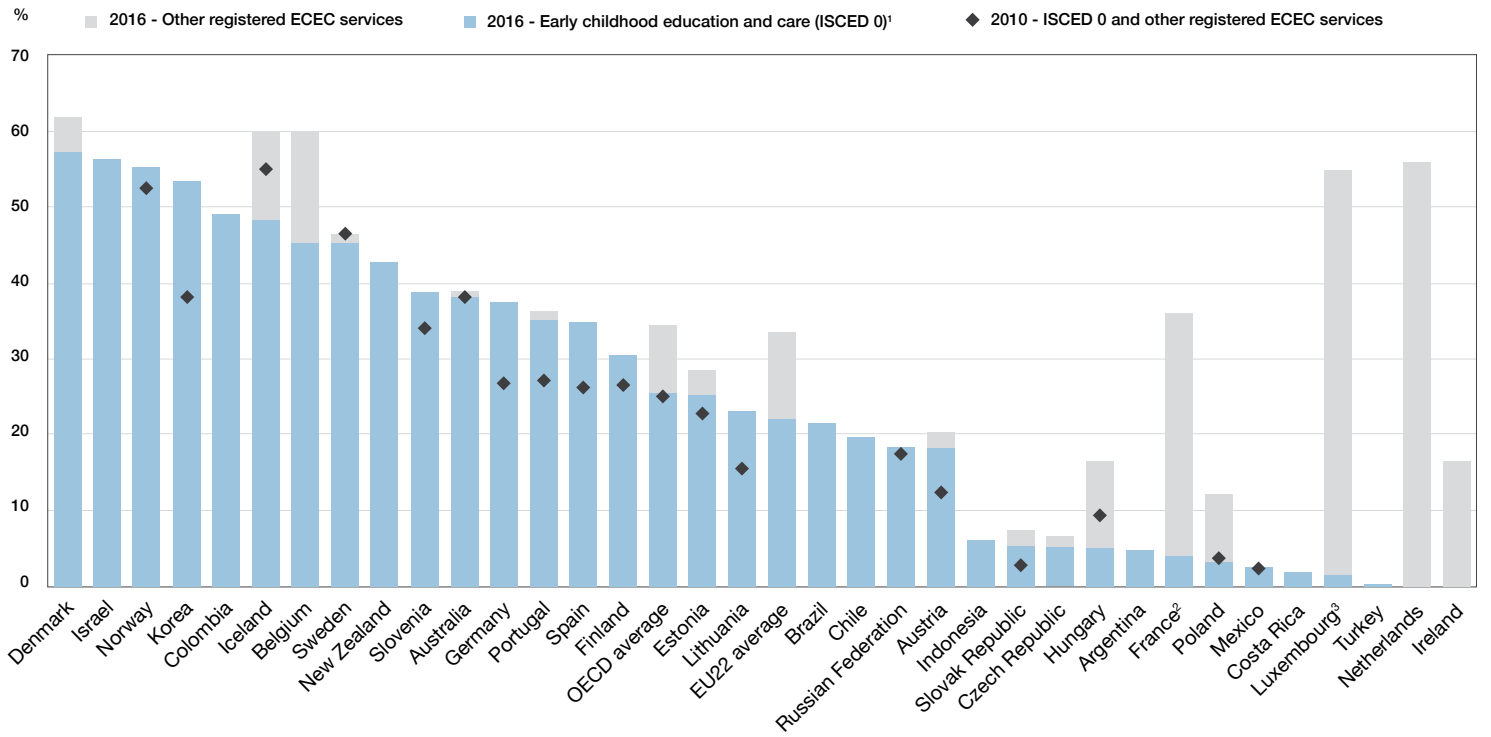

1. According to ISCED criteria.

2. Data for "Other registered ECEC services" come from the survey "Enquête Modes de garde et d'accueil des jeunes enfants 2013 " conducted by the statistical division of the French Ministry for Solidarities and Health (DREES). Figures refer to the primary custody arrangements.

3. Year of reference 2014 instead of 2016 for children under the age of 3 enrolled in "Other registered ECEC services". Data come from the OECD family database (www.oecd.org/els/family/database.htm).

Countries are ranked in descending order of the enrolment rates in ISCED 0 of children under the age of 3 in 2016.

Source: OECD (2018 $\left.{ }^{[2]}\right)$, Education at a Glance 2018: OECD Indicators, https://dx.doi.org/10.1787/eag-2018-en.

to be exposed to an ECEC setting with trained or accredited staff, even before they turn 3. Interestingly, more than half of the OECD countries have or have recently moved towards this kind of system.

In other countries with high enrolment rates, such as France, Luxembourg and the Netherlands, the strategy is different. In those countries, ECEC services for very young children are not in adherence with all ISCED criteria. Policies for "care" and "early education" have developed separately and fall under the responsibility of different authorities. In these countries, childcare refers most commonly to provision for children under the age of 3 and early education most commonly to children aged 3 years or older.

\section{International comparison of ECEC: Some technical improvements still needed}

While significant progress has been made in recent years to ensure the intemational comparability of information on ECEC services, additional efforts are still needed to improve country coverage, further develop the indicators and consider which other ECEC characteristics might affect comparability across countries. In particular, significant differences across countries in the duration of ECEC and the intensity of participation should receive special attention because they make it complex to ensure the comparability and interpretability of indicators on enrolment and financing of ECEC.

On the overall duration of ECEC

Variations among countries over the duration of ECEC programmes have a strong impact on enrolment statistics and the level of expenditure allocated to ECEC. For instance, children in Ireland typically enter primary education at the age of 5 while in Finland they typically enter at 7 (see Figure 2). This explains why the enrolment of 5-year-olds in ECEC in Ireland is low, when in fact it is simply because children of this age are already enrolled in primary education.

This variability between countries also has implications for indicators on expenditure in ECEC. The shorter duration of pre-primary education in Ireland as a result of children's earlier transition into primary education partly explains why the country's expenditure on ECEC as a percentage of gross domestic product (GDP) is below the OECD average. Similarly, late entry into primary education, as in Finland, means children spend longer in ECEC than in other countries and may explain why these countries spend more as a percentage of GDP than the OECD average.

To avoid this distortion, future indicators on ECEC should show expenditure by age and not by ISCED level in order to compare countries' investment over the same period. 


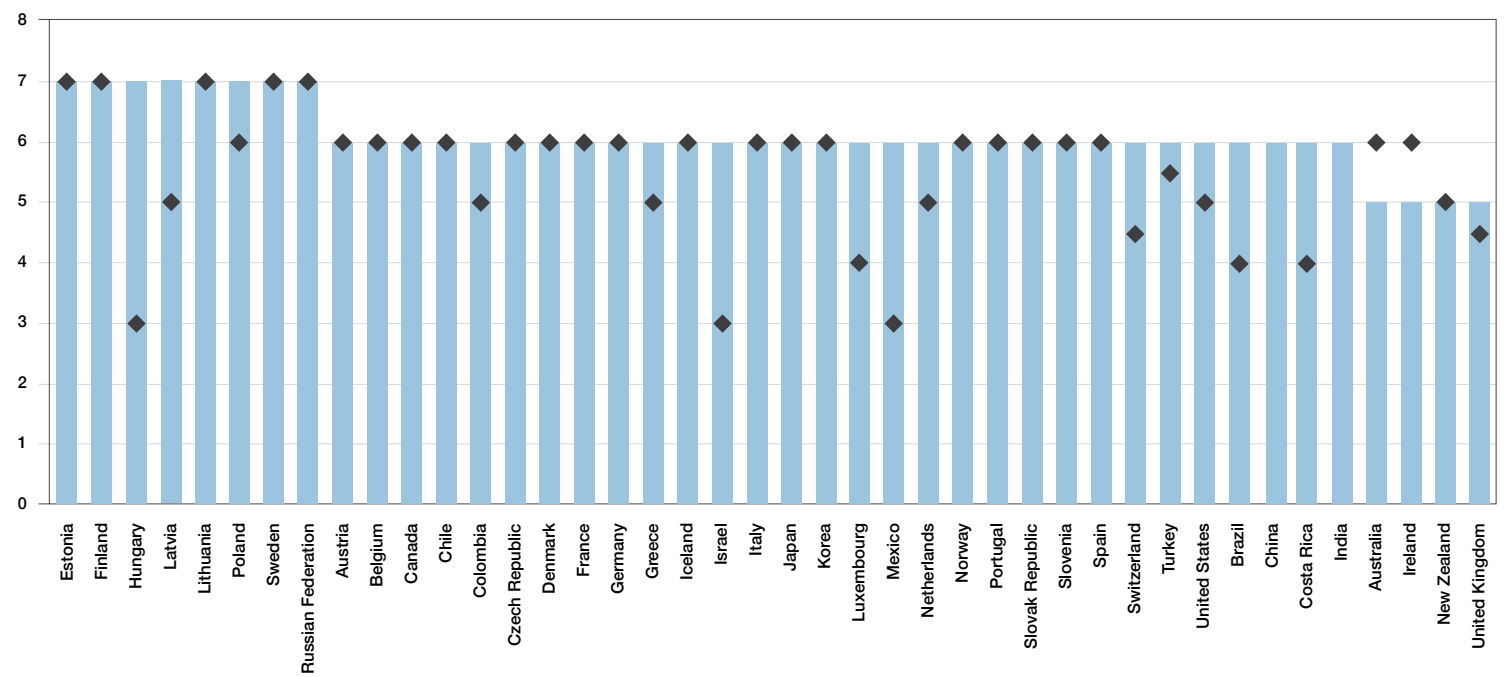

Countries are ranked in descending order of starting age of primary education.

Source: OECD (2018), Education at a Glance Database, http://stats.oecd.org/.

On the intensity of participation (full-time versus part-time attendance)

The concepts used to define full-time and part-time participation at other ISCED levels, such as study load and the academic value or progress that the study represents, are not easily applicable to ISCED level 0. ECEC is not necessarily compulsory for young children in many countries (Figure 2). In addition, the number of hours per week that represent typical full-time enrolment in an education programme at ISCED level 0 varies widely between countries. Because of this, it is not yet possible to express enrolment rates in full-time-equivalents (FTEs) for ISCED level 0 programmes in the same way as for other ISCED levels and only headcounts are reported.

Headcounts are not a satisfactory measure because they do not take into account the differences in intensity of participation in ECEC. For instance, 83\% of children aged 3 to 5 years are enrolled in pre-primary education in both Mexico and the Russian Federation. However, these similar percentages hide wide variations: children attend pre-primary education from 15 hours per week in Mexico but up to 50 hours per week in the Russian Federation.

\section{Box 2. Coverage of early childhood education and care in Education at a Glance indicators and ongoing work}

- Coverage of enrolment statistics

Most statistics on early childhood education and care (ECEC) included in the Education at a Glance (EAG) indicators are based on the ISCED 2011 classification. For instance, indicators on the financing of ECEC and ECEC personnel are shown separately for ISCED 01, ISCED 02 and ISCED 0. However, the coverage of enrolment statistics in EAG differs from the other indicators. Since EAG 2018, the indicators on enrolment of children under the age of 3 have also included other ECEC services that are considered to be an integral part of countries' ECEC provision but do not comply with the ISCED 0 criteria sufficiently to be considered an educational programme.

- Categorisation of ECEC staff

There are a variety of categories of professionals working in ECEC systems. The EAG indicators are exclusively focused on teachers and teachers' aides. Under this classification, teachers and comparable practitioners have the primary responsibility for a group of children at the class or playroom level. In contrast, teachers' aides support the teacher in a group of children or class. They usually have lower qualification requirements than teachers. Teachers' aides are only included in the EAG indicator on children-to-staff ratio.

- $\quad$ Assessing the quality and outcomes of ECEC

The INES development work on ECEC will also benefit in the future from ongoing OECD projects on ECEC over the period 2019-20. For instance, the Teaching and Learning International Survey (TALIS), Starting Strong will contribute to a better understanding of the quality of the learning and well-being environment that children experience. In the same vein, the International Early Learning and Child Well-being Study will assess for the first time the non-cognitive and cognitive learning outcomes of children.

Source: $\left(\mathrm{OECD}, 2018_{[2]}\right.$; OECD, 2017 $\left.{ }_{[1]}\right)$ 


\section{The bottom line}

The types of services available to children and their parents vary significantly across OECD countries This makes international comparisons of ECEC more challenging. The revision of ISCED in 2011 was a significant first step towards better identifying the education component of ECEC programmes and capturing information about ECEC services designed for children under the age of 3. Extending this typology to ECEC services that are considered an integral part of countries' ECEC provision but do not comply with all the ISCED 0 criteria, offers opportunities to better understand enrolment statistics. While much progress has been made in recent years, additional efforts are needed to pursue the development of ECEC indicators to take into account other characteristics that affect the interpretation and comparability of statistics across countries.

\section{REFERENCES :}

[2] OECD (2018), Education at a Glance 2018: OECD Indicators, OECD Publishing, Paris, https://dx.doi.org/10.1787/eag-2018-en.

[1] OECD (2017), Starting Strong 2017: Key OECD Indicators on Early Childhood Education and Care, Starting Strong, OECD Publishing, Paris, https://dx.doi.org/10.1787/9789264276116-en.

[3] OECD/Eurostat/UNESCO Institute for Statistics (2015), ISCED 2011 Operational Manual: Guidelines for Classifying National Education Programmes and Related Qualifications, OECD Publishing, Paris, http://dx.doi.org/10.1787/9789264228368-en.

www.oecd.org/education/education-at-a-glance-19991487.htm

Education Indicators in Focus (previous issues)

PISA in Focus

Teaching in Focus

International Early Learning Study: http:/www.oecd.org/education/

school/the-international-early-learning-and-child-well-being-study-thestudy.htm

TALIS Starting Strong Survey: http://www.oecd.org/education/school/ oecd-starting-strong-teaching-and-learning-international-survey.htm

Photo credit: () Christopher Futcher / iStock; @ Marc Romanelli / Gettyimages; @ michaeljung / Shutterstock; @ Pressmaster / Shutterstock This work is published under the responsibility of the Secretary-General of the OECD. The opinions expressed and arguments employed herein do not necessarily reflect the official views of OECD member countries.

This document, as well as any data and any map included herein, are without prejudice to the status of or sovereignty over any territory, to the delimitation of international frontiers and boundaries and to the name of any territory, city or area.

The statistical data for Israel are supplied by and are under the responsibility of the relevant Israeli authorities. The use of such data by the OECD is without prejudice to the status of the Golan Heights, East Jerusalem and Israeli settlements in the West Bank under the terms of international law. 